\title{
Adjuvant chemoradiotherapy instead of revision radical resection after local excision for high-risk early rectal cancer
}

Jae-Uk Jeong ${ }^{1}$, Taek-Keun Nam ${ }^{1 *}$ D, Hyeong-Rok Kim², Hyun-Jeong Shim³ ${ }^{3}$ Yong-Hyub Kim', Mee Sun Yoon', Ju-Young Song ${ }^{1}$, Sung-Ja Ahn ${ }^{1}$ and Woong-Ki Chung ${ }^{1}$

\begin{abstract}
Background: After local excision of early rectal cancer, revision radical resection is recommended for patients with high-risk pathologic stage T1 (pT1) or pT2 cancer, but the revision procedure has high morbidity rates. We evaluated the efficacy of adjuvant concurrent chemoradiotherapy (CCRT) for reducing recurrence after local excision in these patients.

Methods: Eighty-three patients with high-risk pT1 or pT2 rectal cancer underwent postoperative adjuvant CCRT after local excision. We defined high-risk features as PT1 having tumor size $\leq 3 \mathrm{~cm}$, and/or resection margin (RM) $\leq 3 \mathrm{~mm}$, and/or lymphovascular invasion (LVI), and/or non-full thickness excision such as endoscopic mucosal resection (EMR) or endoscopic submucosal dissection (ESD), or unknown records regarding those features, or pT2 cancer. Radiotherapy was administered with a median dose of 50.4 Gy in 1.8 Gy fraction size over 5-7 weeks. Concurrent 5-fluorouracil and leucovorin were administered for 4 days in the first and fifth weeks of radiotherapy.
\end{abstract}

Results: The median interval between local excision and radiotherapy was 34 (range, 11-104) days. Fifteen patients (18.1\%) had stage pT2 tumors, 22 (26.5\%) had RM of $\geq 3 \mathrm{~mm}$, and 21 (25.3\%) had tumors of $\geq 3 \mathrm{~cm}$ in size. Thirteen patients (15.7\%) had LVI. Transanal excision was performed in 58 patients (69.9\%) and 25 patients (30.1 \%) underwent EMR or ESD. The median follow-up was 61 months. The 5-year overall survival (OS), locoregional relapse-free survival (LRFS), and disease-free survival (DFS) rates for all patients were 94.9, 91.0, and $89.8 \%$, respectively. Multivariate analysis did not identify any significant factors for OS or LRFS, but the only significant factor affecting DFS was the pT stage $(p=0.027)$.

Conclusions: In patients with high-risk pT1 rectal cancer, adjuvant CCRT after local excision could be an effective alternative treatment instead of revision radical resection. However, patients with pT2 stage showed inferior DFS compared to PT1.

Keywords: Local excision, Early rectal cancer, Adjuvant chemoradiotherapy

Abbreviations: 2D, Two-dimensional; 3D, Three-dimensional; 5-FU, 5-fluorouracil; CCRT, Concurrent chemoradiotherapy; $\mathrm{Cl}$, Confidence interval; CT, Computed tomography; DFS, Disease-free survival; EMR, Endoscopic mucosal resection; ESD, Endoscopic submucosal dissection; HR, Hazard ratio; LRFS, Locoregional relapse-free survival; LV, Leucovorin; MRI, Magnetic resonance imaging; N-S, Not significant; OS, Overall survival; PNI, Perineural invasion; PT, Pathologic tumor stage; RM, Resection margin; TAE, Transanal excision

\footnotetext{
* Correspondence: tknam@jnu.ac.kr

'Department of Radiation Oncology, Chonnam National University Medical

School, Hwasun-eup, Hwasun-gun, Jeonnam, South Korea

Full list of author information is available at the end of the article
}

\section{Ciomed Central}

(C) 2016 The Author(s). Open Access This article is distributed under the terms of the Creative Commons Attribution 4.0 International License (http://creativecommons.org/licenses/by/4.0/), which permits unrestricted use, distribution, and reproduction in any medium, provided you give appropriate credit to the original author(s) and the source, provide a link to the Creative Commons license, and indicate if changes were made. The Creative Commons Public Domain Dedication waiver (http://creativecommons.org/publicdomain/zero/1.0/) applies to the data made available in this article, unless otherwise stated. 


\section{Background}

Radical surgery has been the standard of treatment for patients with rectal cancer and adjuvant concurrent chemoradiotherapy (CCRT) is often recommended in order to decrease the risk of recurrence for patients with locally advanced rectal cancer. A randomized controlled study comparing adjuvant CCRT with neoadjuvant CCRT has showed more sphincter preservation, a decreased rate of pelvic recurrence, and a lower incidence of treatmentrelated toxicities in the neoadjuvant CCRT group [1]. In selected cases, local excision after neoadjuvant CCRT had comparable oncologic outcomes to radical surgery, with fewer complications [2], and local recurrence rates of $<20 \%$ have been reported in patients with stage T2 tumors after local excision with neoadjuvant CCRT $[3,4]$.

Transanal excision (TAE) can be performed as an initial treatment in patients with early rectal cancers who have well to moderately differentiated stage T1 tumors that are $<30 \%$ of the circumference, $<3 \mathrm{~cm}$ in size, mobile, non-fixed, and without lymphovascular invasion (LVI) or perineural invasion $[5,6]$. Local excision should be performed in patients with no evidence of lymphadenopathy on pretreatment imaging because lymph node metastasis has been reported at rate of 17 to $31 \%$ in patients with pathologic stage $\mathrm{T} 1$ (pT1) and $\mathrm{pT} 2$ rectal cancers [7].

TAE alone has been associated with a higher instance of local recurrence ( 2.7 vs. $13.2 \%, p=0.001)$ and inferior disease-specific survival when compared to radical surgery for tumors with high-risk pathologic features [5], and revision radical resection is often necessary after local excision for patients with these tumors $[8,9]$. Radical surgery has a $2-3 \%$ perioperative mortality rate and $20-30 \%$ complication rate, including bowel, bladder, and sexual dysfunction and permanent colostomy [10]. Local excision and adjuvant CCRT have been attempted instead of revision radical surgery in order to avoid major morbidities, and local excision with adjuvant CCRT may offer better oncologic outcomes than local excision alone [11-14]. However, the efficacy of adjuvant CCRT after local excision remains controversial, and evidence is lacking, as there are few published reports so far.

We present a retrospective single-center analysis of survival outcomes in a relatively large cohort to investigate the role of adjuvant CCRT after local excision as an alternative to revision radical surgery in patients with early stage high-risk rectal cancers.

\section{Methods}

\section{Patient eligibility}

Patients who received adjuvant CCRT after local excision of rectal cancer between January 2004 and December 2012 were eligible for inclusion. Clinical imaging before local excision included abdominal-pelvic computed tomography
(CT) and/or pelvic magnetic resonance imaging (MRI), and chest CT. Tumor stage was classified in accordance with the American Joint Committee on Cancer staging system, seventh edition. Eligibility criteria included a histological diagnosis of adenocarcinoma, pT1, after local excision of the primary rectal cancer, with high-risk features including tumor size $\geq 3 \mathrm{~cm}$, and/or resection margin (RM) $\leq 3 \mathrm{~mm}$, and/or LVI, and/or non-fullthickness excision such as endoscopic mucosal resection (EMR) or endoscopic submucosal dissection (ESD), or unknown records regarding those features, or pT2 cancer. Patients with no evidence of distant metastasis, no previous history of other cancers, and no previous pelvic radiotherapy were eligible in this analysis. Institutional review board at our institute approved this study.

\section{Adjuvant treatments}

Radiotherapy was performed with 6-MV or 10-MV X-rays via three- or four-field box technique for two-dimensional (2D) or three-dimensional (3D) conformal radiotherapy. The superior border of the 2D field was the sacral promontory, the inferior border was $3 \mathrm{~cm}$ distal to the tumor or the inferior obturator foramen, the lateral border was $1 \mathrm{~cm}$ from the bony pelvis, and the anterior and posterior borders of the lateral portals were at the posterior symphysis pubis and at $1 \mathrm{~cm}$ behind the anterior bony sacrum. The clinical target volume (CTV) for 3D conformal radiotherapy included the primary tumor bed, the mesorectum, and the presacral, obturator, internal iliac, and distal common iliac lymph nodes. The PTV was defined as $0.5 \mathrm{~cm}$ margin around the CTV in all directions. The planned dose to PTV was up to 45.0 Gy in 1.8 Gy fraction size over 5 weeks and an additional boost dose of 5.4 Gy was administered to tumor bed. A concurrent chemotherapy regimen of 5-fluorouracil (5-FU; $425 \mathrm{mg} / \mathrm{m}^{2} /$ day) and leucovorin ( $\mathrm{LV} ; 20 \mathrm{mg} / \mathrm{m}^{2} /$ day) was administered for 4 days during weeks 1 and 5 of radiotherapy, and after completion of the CCRT, adjuvant chemotherapy consisting of 5 -FU ( $425 \mathrm{mg} / \mathrm{m}^{2} /$ day) and LV (20 mg/m²/day) administered for 5 days every 4 weeks, for up to four cycles, was recommended.

\section{Follow-up and statistical analysis}

Regular follow-up visits were scheduled at 3-month intervals following completion of radiotherapy, including sigmoidoscopy and abdominal-pelvic CT or pelvic MRI for up to 2 years, and at 4- to 6-month intervals for the next 3 years. Chest CT was also scheduled to be checked at 6-month intervals. Treatment failure was defined as showing newly developed soft tissue mass or lymph node on CT or MRI, and pathologic confirmation was required for diagnosis of local recurrence. Overall survival (OS) was defined as the time from the start of CCRT to death from any cause or the last follow-up. 
Locoregional relapse-free survival (LRFS) was defined as survival without locoregional recurrence from the start date of CCRT to the date of last follow-up or death from any cause. Disease-free survival (DFS) was defined as the time from the start of therapy to the date of treatment failure or last follow-up. Survival rates were calculated up to 60 months of follow-up in order to remove bias due to death from natural causes among elderly patients surviving more than 60 months.

The Kaplan-Meier method was used to plot survival curves, which were analyzed using log-rank tests to determine prognostic factors in univariate analysis. A Cox regression model was used to identify prognostic factors in the multivariate analysis. All statistical analyses were performed using SPSS, version 19.0 (SPSS Inc., Chicago, IL, USA). A statistically significant difference between groups was indicated at $p<0.05$. Adverse events were defined according to the National Cancer Institute Common Terminology Criteria for Adverse Events (CTCAE), version 4.0.

\section{Results}

\section{Patient characteristics}

During the study period, a total of 90 patients received adjuvant CCRT after local excision for early rectal cancer. Of these, seven patients were excluded, including three who had carcinoma in situ, two who did not have any high-risk features, one who chose to discontinue RT after 7.2 Gy in four fractions, and one who had colectomy for transverse colon cancer 1 month before TAE for the rectal tumor (Fig. 1). Thus, 83 patients (57 men and 26 women, median age 66 years) were included in the study (Table 1 ). The median interval between local excision and the start of CCRT was 34 days (range 11-104). Fifteen patients $(18.1 \%)$ had stage pT2 tumors, 22 (26.5\%) had $\mathrm{RM}$ of $\leq 3 \mathrm{~mm}$, and 21 (25.3\%) had tumors of $\geq 3 \mathrm{~cm}$ in size. Thirteen patients $(15.7 \%)$ had LVI. TAE was performed in 58 patients $(69.9 \%)$ and 25 patients (30.1\%) underwent EMR or ESD. The median radiotherapy dose was 50.4 Gy (range 39.6-59.4 Gy). There were two patients in the study group $(2.4 \%)$ who chose not to

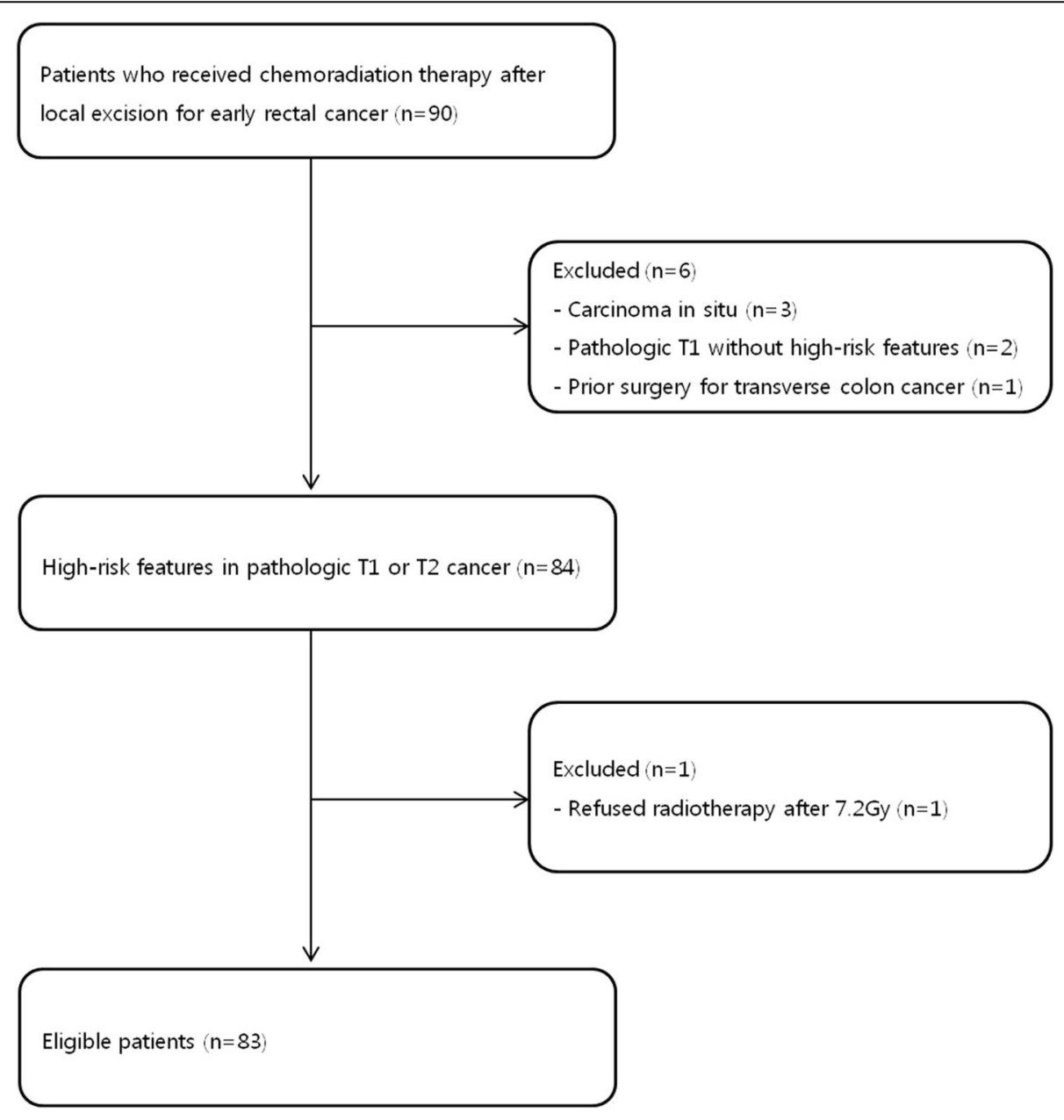

Fig. 1 Eligible patients who received adjuvant chemoradiotherapy after local excision for early rectal cancer with high-risk features 
Table 1 Patient, tumor, and treatment characteristics

\begin{tabular}{lll}
\hline Characteristics & Number of patients & Percent \\
\hline Sex & & \\
Male & 57 & 68.7 \\
Female & 26 & 31.3
\end{tabular}

Age (years)

Median

66

Range

32-84

CEA (ng/mL)

Median

2.36

Range

Unknown

0.5-18.32

9 patients

Tumor size (cm)

Median

2

$0.6-5.2$

Tumor location (cm from anal verge)

$$
\text { Median }
$$

Range

T-stage

1

2

Differentiation

Well differentiated
Moderately differentiated
Poorly differentiated
Unknown

ymphovascular invasion

No
Yes
Unknown

Perineural invasion

$\begin{array}{ll}\text { No } & 42 \\ \text { Yes } & 1\end{array}$

Resection margin

$>3 \mathrm{~mm}$
$\leq 3 \mathrm{~mm}$
Unknown

Local excision

Endoscopic mucosal resection
Endoscopic submucosal dissection
Transanal excision
Radiotherapy (Gy)
Median
Range

55.4

38.6

2.4

3.6

49.4

15.7

34.9

50.6

1.2

48.2

3.6

26.5

69.9

4.8

69.9
Table 1 Patient, tumor, and treatment characteristics (Continued)

\begin{tabular}{lll}
\hline Concurrent chemotherapy & & \\
No chemotherapy & 2 & 2.4 \\
FL & 79 & 95.2 \\
FP & 2 & 2.4 \\
Adjuvant chemotherapy & & \\
No chemotherapy & 69 & 83.1 \\
5-FU & 13 & 15.7 \\
oral 5-FU prodrug & 1 & 1.2 \\
\hline FL 5-fluorouracil + leucovorin, FP 5-fluorouracil + cisplatin, 5-FU 5-fluorouracil
\end{tabular}

receive chemotherapy, and therefore had RT only; there were 14 patients $(16.9 \%)$ who consented to an additional course of adjuvant chemotherapy following the CCRT: 1 of these received five cycles of oral therapy with tegafur and uracil $\left(300 / 672 \mathrm{mg} / \mathrm{m}^{2} /\right.$ day $)$ for 4 weeks per cycle due to travel difficulties; all of the others were to receive the regimen described above (Table 1).

\section{Survival and prognostic factors}

At the time of the final analysis, 75 patients $(90.4 \%)$ had survived without disease and two (2.4\%) were alive with disease. The median duration of follow-up was 61 months. Five-year OS for all 83 patients was $94.9 \%$, with LRFS of $91 \%$, and DFS of $89.8 \%$ (Fig. 2). The variables of sex, age, tumor location, serum carcinoembryonic antigen levels,

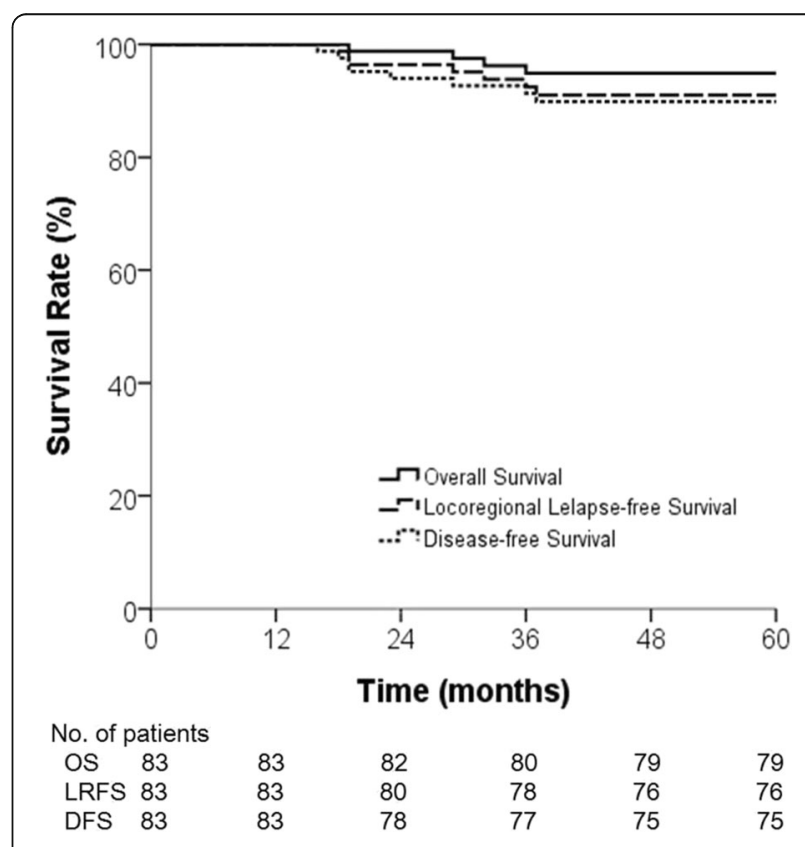

Fig. 2 Overall survival (OS), locoregional relapse-free survival (LRFS), and disease-free survival (DFS) in entire patient cohort 
tumor size, pathologic T stage, RM, LVI, type of local excision, radiation dose, and adjuvant chemotherapy were used for both univariate and multivariate analysis. Age was the only significant factor associated with OS on univariate analysis $(p=0.031)$, and this may have been because death from any cause was considered as an event when calculating survival. According to DFS, pathologic $\mathrm{T}$ stage showed statistical significance in univariate analysis $(p=0.015)$. On multivariate analysis, there were no significant factors for OS or LRFS (Table 2), but pathologic $T$ stage was the only significant factor influencing DFS $(p=0.027)$.

Table 2 Prognostic factors related with overall survival (OS), locoregional relapse-free survival (LRFS), and disease-free survival (DFS)

\begin{tabular}{|c|c|c|c|c|c|c|}
\hline \multirow[b]{3}{*}{ (No. of patients) } & \multicolumn{2}{|l|}{ OS } & \multicolumn{2}{|l|}{ LRFS } & \multicolumn{2}{|l|}{ DFS } \\
\hline & Univariate & $\overline{\text { Multivariate }}$ & Univariate & $\overline{\text { Multivariate }}$ & Univariate & Multivariate \\
\hline & 5 -year rate $(\%)$ & $p$-value & 5 -year rate $(\%)$ & $p$-value & 5 -year rate $(\%)$ & $p$-value \\
\hline Sex & & $n-s$ & & $n-s$ & & $n-s$ \\
\hline Male (57) & 94.4 & & 92.6 & & 90.9 & \\
\hline Female (26) & 95.8 & & 87.6 & & 87.6 & \\
\hline Age & & $n-s$ & & $n-s$ & & $n-s$ \\
\hline$<70(58)$ & $98.2^{\mathrm{a}}$ & & 94.8 & & 93.1 & \\
\hline$\geq 70(25)$ & 86.4 & & 81.0 & & 81.0 & \\
\hline Location from anal verge & & $n-s$ & & $n-s$ & & $n-s$ \\
\hline$<5 \mathrm{~cm}(33)$ & 96.7 & & 93.6 & & 90.7 & \\
\hline$\geq 5 \mathrm{~cm}(50)$ & 93.7 & & 89.4 & & 89.4 & \\
\hline CEA level & & $n-s$ & & $n-s$ & & $n-s$ \\
\hline$<3 \mathrm{ng} / \mathrm{ml}(49)$ & 100 & & 95.6 & & 93.6 & \\
\hline$\geq 3 \mathrm{ng} / \mathrm{ml}(34)^{\mathrm{b}}$ & 87.0 & & 84.0 & & 84.3 & \\
\hline Tumor size & & $n-s$ & & $n-s$ & & $n-s$ \\
\hline$<3 \mathrm{~cm}(62)$ & 94.9 & & 89.7 & & 88.1 & \\
\hline$\geq 3 \mathrm{~cm} \mathrm{(21)}$ & 94.7 & & 94.7 & & 94.7 & \\
\hline T-stage & & $n-s$ & & $n-s$ & & 0.027 (HR: $4.8,95$ \% Cl: 1.2-19.1) \\
\hline $1(68)$ & 95.2 & & 93.7 & & $93.8^{\mathrm{a}}$ & \\
\hline $2(15)$ & 93.3 & & 80.0 & & 73.3 & \\
\hline Resection margin & & $n-s$ & & $n-s$ & & $n-s$ \\
\hline$>3 \mathrm{~mm}(3)$ & 100 & & 100 & & 100 & \\
\hline$\leq 3 \mathrm{~mm}(22)$ & 95.5 & & 86.4 & & 81.8 & \\
\hline Unknown (58) & 94.3 & & 92.1 & & 92.1 & \\
\hline LVI & & $n-s$ & & $n-s$ & & $n-s$ \\
\hline No (41) & 92.1 & & 87.1 & & 84.9 & \\
\hline Yes (13) & 92.3 & & 83.9 & & 83.9 & \\
\hline Unknown (29) & 100 & & 100 & & 100 & \\
\hline Local excision & & $n-s$ & & $n-s$ & & $n-s$ \\
\hline EMR or ESD (26) & 92.0 & & 88.1 & & 88.1 & \\
\hline TAE (57) & 96.2 & & 92.2 & & 90.5 & \\
\hline Radiation dose & & $n-s$ & & $n-s$ & & $n-s$ \\
\hline > 50.4 Gy (8) & 100 & & 100 & & 100 & \\
\hline$\leq 50.4 \mathrm{~Gy}(75)$ & 94.3 & & 90.0 & & 88.7 & \\
\hline Adjuvant chemotherapy & & $n-s$ & & $n-s$ & & $n-s$ \\
\hline Yes (14) & 100 & & 92.9 & & 92.9 & \\
\hline No (69) & 93.9 & & 90.7 & & 89.3 & \\
\hline
\end{tabular}

$N$-S not significant, LVI lymphovascular invasion, EMR endoscopic mucosal resection, ESD endoscopic submucosal dissection, TAE transanal excision, HR hazard ratio, $\mathrm{Cl}$ confidence interval, ${ }^{\mathrm{a}}$ statistically significant in univariate analysis, ${ }^{\mathrm{b}}$ Nine patients of unknown CEA level were included in this subgroup 


\section{Treatment failures and toxicities}

Two of five patients $(2.4 \%)$ with observed treatment failure had isolated local recurrences, two $(2.4 \%)$ had isolated distant recurrences, and one (1.2\%) had simultaneous local and distant recurrence. No regional treatment failures were observed in any patient. Among the five patients with local and distant recurrences, four (80\%) had stage pT2 tumors or surgical RM of $\leq 3 \mathrm{~mm}$. Five-year LRFS for patients with stage pT1 vs. pT2 tumors was 93.7 vs. $80.0 \%$, respectively, but this difference was not significant $(p=0.091)$. However, the 5 -year DFS did differ significantly, at $93.8 \%$ for patients with stage T1 tumors and $73.3 \%$ for those with stage T2 tumors $(p=0.015)$ (Fig. 3). Regarding the two patients who had isolated local failure, one patient received intensitymodulated re-irradiation with 5-FU after re-excision and the other underwent salvage laparoscopic abdominoperineal resection with adjuvant chemotherapy and they had survived without disease at the last follow-up. The patient with loco-distant recurrence had progressive disease despite salvage chemotherapy, and one of the two patients who had isolated distant recurrences was alive after salvage liver metastasectomy, while the other died of disease (Table 3). Grade 2 proctitis occurred in nine patients $(10.8 \%)$, and no grade 3 or higher acute toxicities developed. There were no patients who had Grade 2 or higher late toxicities. Nine patients $(10.8 \%)$ showed proctitis finding without any symptom on regular follow-up proctoscopy. There were no patients who had symptom relating anal sphincter dysfunction.

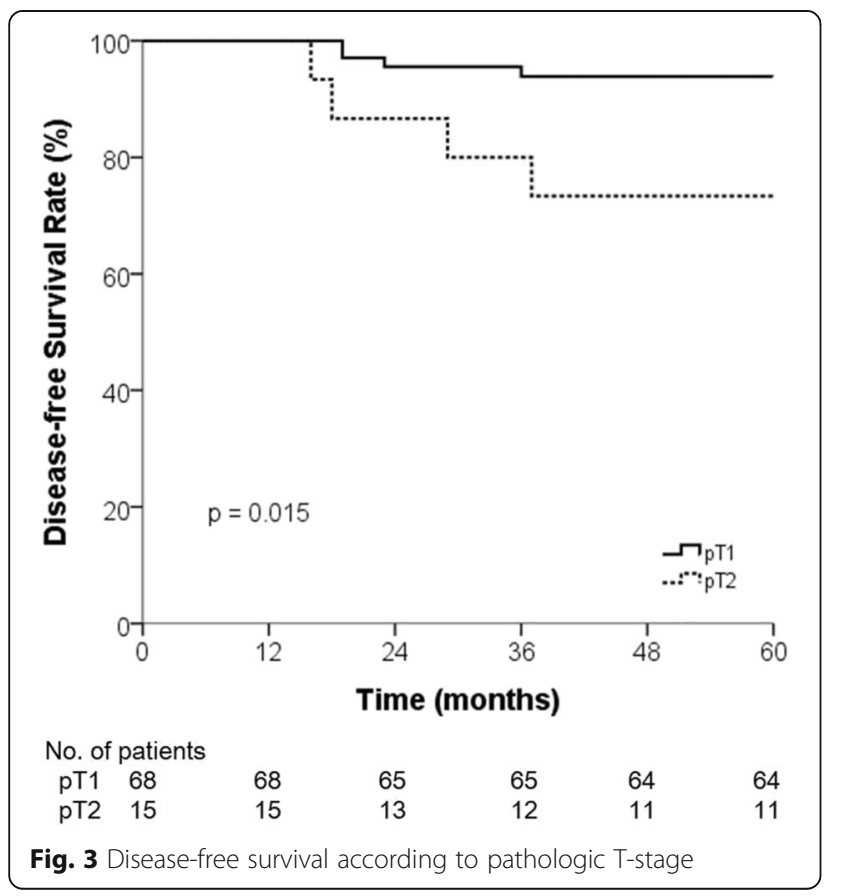

\section{Discussion}

In this study, adjuvant CCRT after local excision was shown to have acceptable oncologic outcomes without severe complications in patients with early rectal cancers that exhibited known high-risk features for locoregional recurrence. Five-year LRFS was $91 \%$ and DFS was $89.8 \%$. There were no significant factors related to OS on multivariate analysis. Neither univariate nor multivariate analysis identified significant factors associated with LRFS in the study, but the only significant factor affecting DFS was the pathologic T stage. This result implies that adjuvant CCRT could allow excellent tumor control for patients with high-risk stage T1 tumors. However, the patients with pT2 tumors survived significantly shorter DFS in this study. In the non-randomized prospective trial, 51 patients with $\mathrm{T} 2$ cancers received CRT after local excision, and 7/51 (14 \%) experienced isolated local recurrence with 4 years median follow-up [15]. But more patients $(18 \%)$ had local recurrence in the updated results with more than 7 years median follow-up [16].

Local excision of early-stage rectal cancers is becoming a more common treatment approach [12]. However, patients may be at higher risk of recurrence after local excision compared to conventional radical resection procedures. Nash et al. reported higher recurrence rates in patients who had local excision compared with those who underwent radical resection for $\mathrm{T} 1$ rectal cancer (13.2 vs. $2.7 \%, p=0.001$ ) [5], and local excision alone for stage pT2 tumors has been associated with a recurrence rate of up to $37 \%$, requiring salvage by radical resection where possible [17]. Adjuvant CCRT after local excision of stage T1 and T2 tumors has been associated with reduced local recurrence rates in several previous studies [11-14]. In one of these, the local recurrence rate among patients with stage T2 tumors who received adjuvant radiotherapy was 9 vs. $36 \%$ among those who did not have adjuvant treatments [13]. In another, among $27 \mathrm{~T} 1$ patients, four of $17 \mathrm{pa}-$ tients with stage T1 tumors who had local excision without adjuvant therapy developed local recurrence (24 \%) while remaining 10 patients with adjuvant CCRT did not [14].

The benefits of local excision may include reduced overall morbidity, avoidance of permanent colostomy instances, reduced mortality, and shorter hospital stay [18]. Morbidity rates of 5.6 vs. $14.5 \%(p<0.001)$ have been reported for patients undergoing local excision vs. radical resection for the initial treatment of stage $\mathrm{T} 1$ tumors [19]. However, salvage surgery for recurrence after initial local excision might result in poor oncologic outcomes and high morbidity [20]. In our study, only three of 83 patients (3.6\%) had local recurrence and none had severe surgical morbidities, such as are seen 
Table 3 Characteristics of patients with treatment failure

\begin{tabular}{|c|c|c|c|c|c|c|c|c|c|c|c|}
\hline Sex & Age & Initial CEA & pT & Excision & Margin & Radiation dose & $\begin{array}{l}\text { Disease-free } \\
\text { interval (Months) }\end{array}$ & Failure site & Salvage treatment & $\begin{array}{l}\text { Months after } \\
\text { recurrence }\end{array}$ & Last status \\
\hline Female & 69 & 2.11 & 2 & TAE & $1.2 \mathrm{~mm}$ & $50.4 \mathrm{~Gy}$ & 18 & $\begin{array}{l}\text { Lt. perirectal } \\
\text { area (IFF) }\end{array}$ & $\begin{array}{l}\text { Laparoscopic mass } \\
\text { excision + CCRT }\end{array}$ & 30 & $\begin{array}{l}\text { Alive } \\
\text { with disease }\end{array}$ \\
\hline Female & 76 & 2.24 & 2 & TAE & unknown & $50.4 \mathrm{~Gy}$ & 37 & rectum (IFF) & $\begin{array}{l}\text { Laparoscopic } \\
\text { APR+ 5-FU }\end{array}$ & 57 & $\begin{array}{l}\text { Alive } \\
\text { without disease }\end{array}$ \\
\hline Male & 69 & 4.75 & 1 & EMR & $1 \mathrm{~mm}$ & $50.4 \mathrm{~Gy}$ & 19 & $\begin{array}{l}\text { rectum (IFF), } \\
\text { liver, lung }\end{array}$ & Capecitabine & 32 & $\begin{array}{l}\text { Alive } \\
\text { with disease }\end{array}$ \\
\hline Male & 68 & 2.04 & 2 & TAE & $0 \mathrm{~mm}$ & $50.4 \mathrm{~Gy}$ & 16 & liver & $\begin{array}{l}\text { liver S6 } \\
\text { segmentectomy }\end{array}$ & 87 & $\begin{array}{l}\text { Alive without } \\
\text { disease }\end{array}$ \\
\hline Male & 67 & unknown & 1 & TAE & unknown & $48.6 \mathrm{~Gy}$ & 23 & liver & No & 9 & $\begin{array}{l}\text { Dead } \\
\text { with disease }\end{array}$ \\
\hline
\end{tabular}

CEA carcinoembryonic antigen, $p T$ pathologic T-stage, TAE transanal excision, IFF in-field failure, CCRT concurrent chemoradiotherapy, APR abdominoperineal resection,

5-FU 5-fluorouracil, EMR endoscopic mucosal resection

more frequently after radical resection. However, local excision alone cannot provide information on the regional lymph node status, and there is a known 5-10\% risk of occult lymph node metastases in patients with stage T1 tumors and a $20-35 \%$ risk in those with stage T2 lesions [7]. The finding that there were no regional recurrences among the patients in our study suggests that adjuvant CCRT after local excision may have decreased the risk of regional recurrence by controlling regional subclinical disease.

There are several well-known risk factors for recurrence after local excision [21]. Stage T2 lesions have a higher rate of local recurrence compared with $\mathrm{T} 1$ lesions [19], and radical surgery or adjuvant treatment should be routine for patients with stage pT2 tumors after local excision. Patients with stage pT2 tumors who were treated with local excision followed by RT have been shown to have improved OS compared to those who have local excision only [12]. Rackley et al. recommend radical resection instead of local excision with adjuvant therapy for patients with stageT2 tumors because of inferior local control compared to T1 disease [22]. However, they do recommend local excision with adjuvant radiotherapy as a good alternative for patients with stage pT2 tumors who are not candidates for revision radical surgery. Failure to obtain a clear RM is also a well-known risk factor for local recurrence. Gopaul et al. reported that the RM was a significant factor in local treatment failure in patients treated with local excision [13]. The National Comprehensive Cancer Network $^{\bullet}$ guideline recommends RM of $>3 \mathrm{~mm}$ for TAE [23]. In our study, LRFS and DFS were worse among 22 patients with RM of $\leq 3 \mathrm{~mm}$ compared to those with RM of $>3 \mathrm{~mm}$, but the difference was not significant (Table 2).

Radiation doses may be varied according to the extent of the RM. In one series, a dose of 50-56 Gy was recommended in general, but if the RM was $<3 \mathrm{~mm}$, the dose was raised to $59.4-65$ Gy. One in 33 patients with margins of $<3 \mathrm{~mm}$ and one in 18 patients with margins of $\geq 3 \mathrm{~mm}$ had locoregional recurrence [11]. In our study, all three patients with local recurrence had radiation doses of $50.4 \mathrm{~Gy}$, but they had stage pT2 tumors or RM of $\leq 3 \mathrm{~mm}$ (Table 3). There were no treatment failures among eight patients who received doses of $>50.4$ Gy. Among these eight patients, four (50\%) had stage pT2 tumors or RM of $\leq 3 \mathrm{~mm}$, and all received doses of $54.0 \mathrm{~Gy}, 2$ having LVI received 52.2 Gy and 54.0 Gy, respectively, and no details on RM were available for the remaining two, who received 59.4 Gy and 54.0 Gy, respectively.

There are some limitations to this study. First, this study is limited by the retrospective nature and the study period spanned 9 years. During that period, there might be some inherent biases among patient or treatment characteristics. We could not obtain pathological information regarding high-risk pathologic features such as LVI or RM for many patients, as shown in Table 1. However, we classified these patients as having potentially high-risk features, considering that referral by the surgeon for adjuvant CCRT might be due to the surgeon's observation of potential high-risk features. Secondly, 14 patients $(16.5 \%)$ received adjuvant chemotherapy after completion of adjuvant CCRT. However, there were but no significant differences in clinicopathological features between patients who received adjuvant chemotherapy and those who did not (data not shown).

\section{Conclusion}

We found adjuvant CCRT after local excision could be an effective alternative treatment instead of revision radical resection in patients with high-risk pT1 rectal cancer. However, patients with pT2 stage showed inferior DFS compared to $\mathrm{pT} 1$.

\section{Acknowledgement \\ No special acknowledgement.}

Funding

No specific funding. 


\section{Availability of data and materials}

Not applicable.

\section{Authors' contribution}

JJ participated in acquisition of data, interpretation of data, and making draft of the manuscript. TN designed and conceived of this study, and participated in analysis, interpretation of data, and making draft of the manuscript. HK mainly participated in surgery and referred patients for postoperative adjuvant CCRT. HS mainly participated in performing chemotherapy to patients. JS mainly participated in radiotherapy planning. YK, MY, SA and WC participated in interpretation of data, and revising it critically for important intellectual content. All authors read and approved the final manuscript.

\section{Competing interests}

The authors declare that they have no competing interests.

\section{Consent for publication}

Not applicable because of a retrospective analysis without disclosure of personal information.

\section{Ethics approval and consent to participate}

Not applicable because of a retrospective review of previous medical records.

\begin{abstract}
Author details
'Department of Radiation Oncology, Chonnam National University Medical School, Hwasun-eup, Hwasun-gun, Jeonnam, South Korea. ${ }^{2}$ Department of Surgery, Chonnam National University Medical School, Hwasun-eup, Hwasun-gun, Jeonnam, South Korea. ${ }^{3}$ Department of Hemato-Oncology, Chonnam National University Medical School, Hwasun-eup, Hwasun-gun, Jeonnam, South Korea.
\end{abstract}

Received: 14 May 2016 Accepted: 31 August 2016

\section{Published online: 05 September 2016}

\section{References}

1. Sauer R, Becker H, Hohenberger W, Rödel C, Wittekind C, Fietkau R, et al. Preoperative versus postoperative chemoradiotherapy for rectal cancer. New Engl J Med. 2004:351(17):1731-40.

2. Shaikh I, Askari A, Ourû S, Warusavitarne J, Athanasiou T, Faiz O. Oncological outcomes of local excision compared with radical surgery after neoadjuvant chemoradiotherapy for rectal cancer: a systematic review and meta-analysis. Int J Colorectal Dis. 2015;30(1):19-29.

3. Lezoche E, Baldarelli M, Lezoche G, Paganini AM, Gesuita R, Guerrieri M. Randomized clinical trial of endoluminal locoregional resection versus laparoscopic total mesorectal excision for T2 rectal cancer after neoadjuvant therapy. Br J Surg. 2012;99(9):1211-8.

4. Garcia-Aguilar J, Shi Q, Thomas Jr CR, Chan E, Cataldo P, Marcet J, et al. A phase II trial of neoadjuvant chemoradiation and local excision for T2NO rectal cancer: preliminary results of the ACOSOG Z6041 trial. Ann Surg Oncol. 2012;19(2):384-91

5. Nash GM, Weiser MR, Guillem JG, Temple LK, Shia J, Gonen M, et al. Longterm survival after transanal excision of T1 rectal cancer. Dis Colon Rectum. 2009;52(4):577-82.

6. Willett CG, Compton CC, Shellito PC, Efird JT. Selection factors for local excision or abdominoperineal resection of early stage rectal cancer. Cancer. 1994;73(11):2716-20

7. Brodsky JT, Richard GK, Cohen AM, Minsky BD. Variables correlated with the risk of lymph node metastasis in early rectal cancer. Cancer. 1992:69(2):322-6.

8. Nascimbeni R, Burgart LJ, Nivatvongs S, Larson DR. Risk of lymph node metastasis in T1 carcinoma of the colon and rectum. Dis Colon Rectum. 2002;45(2):200-6.

9. Yamamoto $\mathrm{S}$, Watanabe $\mathrm{M}$, Hasegawa $\mathrm{H}$, Baba H, Yoshinare $\mathrm{K}$, Shiraishi J, et al. The risk of lymph node metastasis in T1 colorectal carcinoma. Hepatogastroenterology. 2004;51(58):998-1000.

10. Heafner TA, Glasgow SC. A critical review of the role of local excision in the treatment of early (T1 and T2) rectal tumors. J Gastrointest. 2014;5(5):345-52.

11. Russell AH, Harris J, Rosenberg PJ, Sause WT, Fisher BJ, Hoffman JP, et al. Anal sphincter conservation for patients with adenocarcinoma of the distal rectum: long-term results of radiation therapy oncology group protocol 89-02. Int J Radiat Oncol Biol Phys. 2000;46(2):313-22.
12. Stitzenberg KB, Sanoff HK, Penn DC, Meyers MO, Tepper JE. Practice patterns and long-term survival for early-stage rectal cancer. J Clin Oncol. 2013; 31(34):4276-82.

13. Gopaul D, Belliveau P, Vuong T, Trudel J, Vasilevsky CA, Corns R, et al. Outcome of local excision of rectal carcinoma. Dis Colon Rectum. 2004; 47(11):1780-8.

14. Lamont JP, McCarty TM, Digan RD, Jacobson R, Tulanon P, Lichliter WE. Should locally excised $\mathrm{T} 1$ rectal cancer receive adjuvant chemoradiation? Am J Surg. 2000;180(6):402-6.

15. Steele Jr GD, Herndon JE, Bleday R, Russell A, Benson 3rd A, Hussain M, et al. Sphincter sparing treatment for distal rectal adenocarcinoma. Ann Surg Oncol. 1999;6(5):433-41.

16. Greenberg JA, Shibata D, Herndon 2nd JE, Steele Jr GD, Mayer R, Bleday R. Local excision of distal rectal cancer: an update of cancer and leukemia group B 8984. Dis Colon Rectum. 2008;51 (8):1185-91.

17. Garcia-Aguilar J, Mellgren A, Sirivongs P, Buie D, Madoff RD, Rothenberger DA. Local excision of rectal cancer without adjuvant therapy: a word of caution. Ann Surg. 2000;231(3):345-51.

18. Kidane B, Chadi SA, Kanters S, Colquhoun PH, Ott MC. Local resection compared with radical resection in the treatment of T1NOMO rectal adenocarcinoma: a systematic review and meta-analysis. Dis Colon Rectum. 2015:58(1):122-40.

19. You YN, Baxter NN, Stewart A, Nelson H. Is the increasing rate of local excision for stage I rectal cancer in the United States justified?: a nationwide cohort study from the National Cancer Database. Ann Surg. 2007;245(5):726-33.

20. Bentrem DJ, Okabe S, Wong WD, Guillem JG, Weiser MR, Temple LK, et al. T1 adenocarcinoma of the rectum: transanal excision or radical surgery? Ann Surg. 2005;242(4):472-7.

21. Bach SP, Hill J, Monson JR, Simson JN, Lane L, Merrie A, et al. A predictive model for local recurrence after transanal endoscopic microsurgery for rectal cancer. Br J Surg. 2009;96(3):280-90.

22. Rackley TP, Ma RM, Brown CJ, Hay JH. Transanal local excision for patients with rectal cancer: can radiation compensate for what is perceived as a non-definitive surgical approach? Dis Colon Rectum. 2016;59(3):173-8.

23. National Comprehensive Cancer Network Clinical Practice Guidelines in Oncology ${ }^{\oplus}$ v.2. 2016 Available at: https:/www.nccn.org/professionals/ physician_gls/f_guidelines.asp. Accessed 11 Apr 2016.

\section{Submit your next manuscript to BioMed Central and we will help you at every step:}

- We accept pre-submission inquiries

- Our selector tool helps you to find the most relevant journal

- We provide round the clock customer support

- Convenient online submission

- Thorough peer review

- Inclusion in PubMed and all major indexing services

- Maximum visibility for your research

Submit your manuscript at www.biomedcentral.com/submit
) Biomed Central 